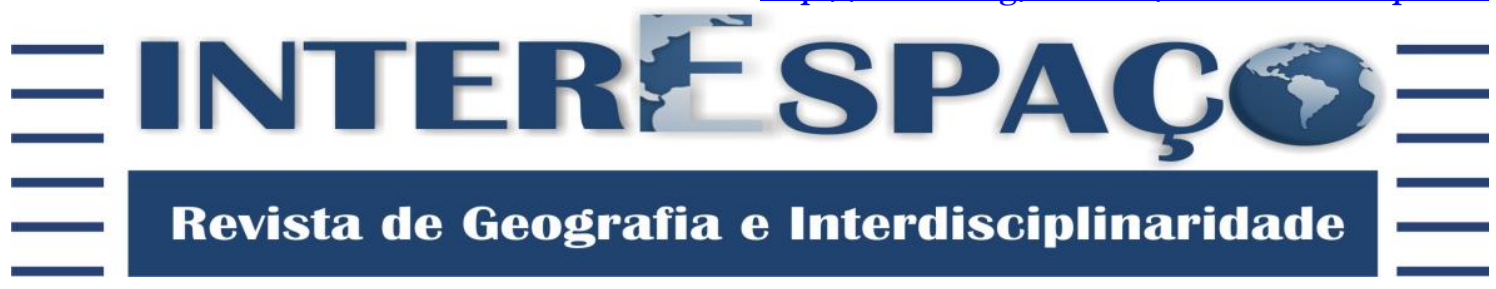

\section{MEMÓRIA E SENTIDO A PARTIR DA CIDADE DE SÃO LUÍS DO MARANHÃO}

\author{
Antonio José de Araújo Ferreira \\ Doutor em Geografia Humana pela Universidade de São Paulo - USP. Professor \\ Associado do Departamento de Geociências da Universidade Federal do Maranhão - \\ UFMA. \\ ajaf@ufma.br
}

\section{RESUMO}

Em oito de setembro de 2012 a capital do estado do Maranhão, São Luís, completou quatro séculos de existência, o que foi comemorado por toda a sociedade em que relevaram-se as transformações, saudosismo e estágio atual. O objetivo deste artigo é refletir sobre Memória e Sentido enquanto possibilidade de analisar o passado e vislumbrar o futuro dessa Cidade, que desde 1997 é Patrimônio Cultural da Humanidade e encabeça uma região metropolitana. Para tanto, utilizaram-se os seguintes procedimentos metodológicos: levantamento bibliográfico, cartográfico, documental e iconográfico; análise e seleção dos dados e informações obtidos; visita técnica a lugares que outrora e atualmente refletem e/ ou fazem parte do cotidiano da cidade de São Luís; interpretação dos dados e informações obtidos. A partir de três períodos (1612-1950; 1951-1996; e 2000-2010) recorre-se à importância da Memória como forma de revisitar a realidade empírica e apreender o Sentido da conformação da Cidade de São Luís. Concluiu-se que através das memórias da capital maranhense consegue-se analisar elementos e conteúdos, que desvendam as mudanças indicadas na periodização, sendo que no mais recente momento (2010-2016) destacam-se os porquês das substituições de uso do solo, novos hábitos e readaptações, aliados à necessidade do cidadão querer viver bem e cada vez melhor.

Palavras-chave: Transformações; Memória; Capital maranhense.

\section{MEMORY AND DIRECTION FROM THE CITY OF SÃO LUÍS DO} MARANHÃO

\section{ABSTRACT}

In 8 September 2012 the capital of the state of Maranhão, São Luís, completed four centuries of existence, which was celebrated by the whole society in which revealed that the transformations, nostalgia and current stage. The purpose of this article is to reflect on memory and meaning as possible to analyze the past and envision the future of this City, which since 1997 is a Cultural Heritage of Humanity and tops a metropolitan region. To this end, we used the following methods: literature survey, cartographic, documentary and iconographic; analysis and selection of data and information obtained; technical visits to places that once and now reflect and/ or are part of everyday life in the city of São Luís; interpretation of the data and information obtained. From three periods (1612-1950; 1951-1996; and 2000-2010) refers to the importance of memory as a way to revisit the empirical reality and grasp the meaning of the conformation of the city of São Luís. It was concluded that through the memories of the capital of Maranhão achieves to analyze elements and contents, which unveil the changes indicated in the periodization, and in more recent times 
(2010-2016) there are the whys of replacements of land use, new habits and adaptations, allied to the need of the citizen wanting to live well and better every time.

Keywords: Transformations; Memory; Capital of Maranhão.

\section{LA MEMORIA Y LA DIRECCIÓN DESDE LA CIUDAD DE SÃO LUÍS DO MARANHÃO}

\section{RESUMEN}

En 8 de septiembre de 2012, la capital del estado de Maranhão, São Luís, completado cuatro siglos de existencia, que fue celebrado por toda la sociedad en la que reveló que las transformaciones, la nostalgia y la etapa actual. El propósito de este artículo es reflexionar sobre la memoria y significado como sea posible para analizar el pasado y avizorar el futuro de esta ciudad, que desde 1997 es Patrimonio Cultural de la Humanidad y encabeza una región metropolitana. Para ello, se utilizaron los siguientes métodos: estudio de la bibliografía, cartografía, documentales e iconográficas; análisis y selección de los datos y la información obtenida; visitas técnicas a lugares que una vez y ahora reflejan y/ o son parte de la vida cotidiana en la ciudad de São Luís; la interpretación de los datos y de la información obtenida. A partir de tres períodos (1612-1950; 1951-1996; y 2000-2010) se refiere a la importancia de la memoria como una manera de volver a la realidad empírica y captar el significado de la conformación de la ciudad de São Luís. Se concluyó que a través de los recuerdos de la capital de Maranhão logra analizar elementos y contenidos, que revelan los cambios indicados en la periodización, y en tiempos más recientes (2010-2016) existen los porqués de reemplazos de uso de la tierra, nuevos hábitos y adaptaciones, aliada a la necesidad del ciudadano de querer vivir bien y cada vez mejor.

Palabras clave: Transformaciones; Memoria; Capital del estado de Maranhão.

"Sem memória não existimos, sem responsabilidade talvez não mereçamos existir." José Saramago.

\section{INTRODUÇÃO}

No dia oito de setembro de 2012 a capital do estado do Maranhão, São Luís, completou seu quarto centenário, o que foi demasiadamente comemorado e concorreu para que o Grupo de Pesquisa em Linguagem e Discurso (GPELD) do Departamento de Letras da Universidade Federal do Maranhão (UFMA) organizasse o I Seminário Nacional a fim de diferentes especialistas debaterem sobre "Cidades e sentidos: pelas vias da memória". Referido tema, convém relevar, tem sido objeto de estudo de vários ramos do conhecimento, entre os quais a Geografia Histórica Urbana que vem contribuindo com reflexões tanto críticas quanto criativas. Tal fato exige diálogos cada vez mais integrados e interdisciplinares com a Arquitetura, a Arqueologia, a Economia, o Planejamento, a Sociologia, a Antropologia. Isso porque a cidade é um produto histórico e social. 
Portanto, este texto resultou de ponderações atinentes à abordagem dessa temática em decorrência da pesquisa levada a cabo entre 2010 e 2012, a qual analisou a produção do espaço urbano na capital maranhense e que foi publicada em forma de livro intitulado "A produção do espaço urbano em São Luís do Maranhão: passado e presente; há futuro?” (FERREIRA, 2014).

Nosso propósito, nesse artigo, é utilizar a Geografia Histórica Urbana na interpretação dos elementos e conteúdos que concorreram e concorrem para a transformação de São Luís, que apesar das praias poluídas continua encantando visitantes e sendo descrita/ registrada em prosa e verso, fotografias, gravuras, filmes, documentários, entre outros meios, os quais remetem ao binômio Sentido e Memória.

Para tanto, utilizaram-se os seguintes procedimentos metodológicos: levantamento bibliográfico (monografia, dissertação, tese, periódico e livro), cartográfico (croqui, mapa), documental (leis e relatórios) e iconográfico (fotografias, imagens e gravuras); análise e seleção dos dados e informações obtidos; visita técnica a lugares que outrora e atualmente refletem e/ ou fazem parte do cotidiano da cidade de São Luís; interpretação dos dados e informações obtidos.

O texto a seguir foi dividido em três partes: a primeira trata de ponderações sobre Cidade, conteúdo e Memória; a segunda analisa tais ponderações a partir da realidade empírica da Cidade de São Luís, cujo percurso cobre quatro séculos e o momento atual; a terceira equivale às conclusões.

\section{SOBRE CIDADE, CONTEÚDO E MEMÓRIA}

Partindo da premissa de que o processo de crescimento das cidades é histórico e por isso tem conteúdo, Sentido e Memória, constata-se que no início do século XIX, por exemplo, somente $2 \%$ da população mundial moravam em núcleos urbanos, o que ascendeu para 10\% no princípio do século XX, sendo que em 2011 a Organização das Nações Unidas (ONU) revelou que correspondia a 50\%, enquanto em 2015, mundialmente, haviam quinze cidades com mais de 10 milhões de habitantes, entre as quais uma brasileira, São Paulo. Esses fatores concorreram para que as cidades, gradativamente, tornassem-se objeto de estudo de diversos ramos do conhecimento por envolver uma gama de elementos passíveis de análise e, que são decorrentes de articulações de fatores políticos, sociais, econômicos, ambientais e espaciais. 
Convém ressaltar, que a urbanização não é só acréscimo populacional uma vez que abrange a divisão social e técnica do trabalho, desenvolvimento tecnológico, "controle" do meio natural, complexidade da organização social, introdução/ assimilação de novos valores socioculturais, presença de equipamentos de consumo coletivo, bens e serviços mais diversificados e sofisticados; com ela, também emergem e são mais evidenciadas as contradições da sociedade.

Mesmo a urbanização sendo um processo mundial, sua materialização na unidade de análise (cidade) requer ponderações no sentido de evitarem-se comparações esdrúxulas porque não existe uma definição internacional e única de cidade; por exemplo, conforme levantamento da ONU o qual incluiu 133 países, Clark (1991) revelou que desse total 48,87\% utilizavam o critério legal (quando a lei definiu o que é a cidade e seu perímetro), 24,81\% o do tamanho da população, 15,04\% o tamanho da população mais um adicional (maioria da população economicamente ativa estando vinculada aos setores secundário e terciário) e 11,28\% tampouco informaram o critério adotado.

No entanto, para o senso comum o que define cidade é o tamanho da população. Este critério, todavia, inclui aglomerações que variam de no mínimo 200 habitantes (Dinamarca), passando para 2.500 (Venezuela) até 10.000 (Suécia e Senegal), sendo que para a ONU tal número deve ser igual a 20.000 residentes. Já nos Estados Unidos e na Índia são utilizados o tamanho da população mais critério adicional. O critério legal é adotado na Tailândia onde são consideradas cidades as municipalidades, enquanto em Marrocos os centros urbanos; na Inglaterra e Gales levam-se em conta os objetivos de governo local (burgos de comarcas, distritos municipais e distritos urbanos); este é o critério adotado no Brasil, que inclui as zonas urbanas e suburbanas de centros administrativos dos municípios e distritos.

Em termos históricos, vale ressaltar que, no Brasil desde a

[...] Colônia, os núcleos urbanos ou vilarejos resultaram da ação urbanizadora das autoridades coloniais, não da criação espontânea da massa; a formação de cidades e vilas é sempre um ato da iniciativa oficial. Essa política continuou a ser praticada no Império através das colônias militares no interior do País e de núcleos de colonização nos Estados. É que os aglomerados urbanos só se desenvolviam espontaneamente no litoral, em virtude do tipo de economia prevalente, voltada para o comércio exterior, até o ciclo do café (SILVA, 1997, p. 17).

Com o ciclo da indústria, a contar de 1930, a população citadina ampliou-se e interiorizou-se; o Instituto Brasileiro de Geografia e Estatística (IBGE) revelou que em 1970 a população urbana ultrapassou a rural e o censo demográfico de 2010 evidenciou que 
$84,4 \%$ dos brasileiros moravam nas cidades, o que tornou esse País um dos mais urbanizados do mundo. Mas, este critério corresponde ao fato urbano? Não, haja vista que, por exemplo, baseado no que é adotado pela ONU (20.000 habitantes), a taxa de urbanização do Brasil é bem menor.

Ainda assim, "a característica marcante da cidade, no Brasil, consiste no fato de ser um núcleo urbano, sede de governo municipal” (SILVA, 1997, p. 20), cujo número oficial passou de 1.574 em 1940 para 2.423 em 1958 e hoje em dia são 5.570. Apesar do acelerado ritmo do processo de urbanização brasileiro, a reflexão sobre seu conteúdo foi lenta e somente avançou por meio das contribuições de estudiosos como Geiger (1963), Santos (1994), Spósito (2007), Oliveira et al. (2014) e Carlos et al. (2015), entre outros.

Convém destacar, que na escala internacional a necessidade de compreender o conteúdo da cidade fez com que alguns esforços fossem levados a cabo, a exemplo de Ebenezer Howard (Cidades-jardins de amanhã) e Lewis Mumford (A cidade na história), sendo que para este "Antigamente, a cidade era o mundo, hoje o mundo é uma cidade"; Kevin Lynch se preocupou com a "imagem" enquanto Henri Lefebvre (1984) e Agnes Heller (1985) ressaltaram o "cotidiano". O que dizer do Sentido e do conteúdo que a cidade de New York tem/revela para o cineasta norte-americano Woody Allen em seu filme "Noivo Neurótico, Noiva Nervosa", de 1977?

A cidade, para Milton Santos (2007), apresenta "fluxos" e "fixos", tem "ritmo", mas é onde a "cidadania" deve ser exercida em sua plenitude. No livro "Ensaio sobre a cegueira", José Saramago (1995) coloca em xeque os valores e contradições de citadinos que ao serem acometidos por uma patologia que, gradativamente, compromete a visão também deparam-se com empecilhos, oportunidades, individualidade e solidariedade. Em se tratando de empecilhos que a cidade oferece, pode-se relevar: qual sentido tem uma cidade para os praticantes do Le Parkour, os quais advogam que "se aprende que viver é superar obstáculos"? Zygmunt Bauman (2009) trata de um assunto que aflige muitas pessoas em "Confiança e Medo na Cidade", mas que guardadas as devidas proporções vale para qualquer núcleo urbano do Mundo. Desvendar a cidade, contudo, para David Harvey (1980; 2005; 2011; 2014) requer uma análise assentada na origem do conteúdo principal, isto é, a "produção capitalista do espaço" que é dinâmica e tem uma lógica e, certamente, Memória decorrente das readaptações vinculadas ao contexto histórico.

$\mathrm{Na}$ escala nacional, entre outros, merecem destaque as análises sobre a realidade empírica de Curitiba (SANTOS, 1995) e São Paulo (BOSI, 2003), sendo que a secretaria de turismo desta última elaborou em 2009 um sugestivo "mapa das sensações". A cidade, 
portanto, apresenta uma gama de elementos e conteúdos que podem ser estudados por diferentes ramos do conhecimento e cabe aos pesquisadores os questionamentos sobre o tempo (passado, presente ou futuro) e a escala (local, estadual, regional, nacional, mundial) a serem considerados e a ênfase a ser priorizada em função da realidade a ser analisada.

Os referidos questionamentos podem ter como inferência o fato de que a cidade é historicamente o lugar em que se discute/faz política, o que para os ocidentais é vinculado à polis grega do século V a.C., em que a democracia emergiu como método de tomar decisões; por isso o status de sede diferencia a cidade de outros lugares como o povoado e a vila, o que pressupõe um conteúdo ímpar. Neste caso, a atividade política exercida na cidade, principalmente nas de porte maior e da atualidade pode influenciar toda a sociedade em que estão inseridas, a exemplo da "Guerrilha Verde" em New York (1973), do Movimento “Occupy London” (2011 e 2012), e do “Occupy Wall Street”, em 2011, o qual foi analisado por David Harvey em "Cidades Rebeldes" (2014).

No Brasil, o uso da cidade enquanto espaço de se fazer política pode ser vinculado, mais recentemente, a movimentos como o "Diretas Já" (1984), o "Caras Pintadas" (1992) e o "Movimento Passe Livre" (MPL). Este último teve início em 13/06/2013, mais precisamente em ruas, avenidas e praças da capital paulista, de maneira que foi repetido nos dias seguintes e em 20/06/2013 já havia sido replicado em 11 capitais e 100 cidades, entre as quais São Luís do Maranhão. A "voz das ruas" exigia dos três níveis de governo melhorias no transporte, educação e saúde pública, além da não aprovação/arquivamento da Proposta de Emenda Constitucional n ${ }^{\circ} 37$, a qual limita o poder de investigação do Ministério Público. Por conseguinte, questionou-se: qual o real papel do Estado?

O que se evidenciou com esse último movimento político foi o tempo transcorrido e as memórias (os porquês? Os lugares de reunião/passeatas? Resultados?) entre os mesmos uma vez que os cidadãos que deram "voz às ruas" não tinham sido instigados por quaisquer associações, sindicatos e/ ou partidos políticos, mas por jovens que naquele ano levaram seus filhos, assim como por adolescentes que pensava-se serem "pacatos". A esses foram associadas pessoas de faixa etária maior e igualmente dispostas a recolocar a política em discussão. A cidade, portanto, tornou-se o lugar de difusão dessa discussão.

Esses componentes remetem ao debate sobre Sentido e Memória na Cidade, conceitos que podem ser conduzidos mediante a interpretação da Geografia Histórica Urbana, embora os elementos passíveis de análise apresentem um leque bem mais abrangente. 
Em decorrência dos efeitos históricos, portanto, um dos elementos de análise do processo de urbanização que passou a ser enfatizado foi a "memória". Esta pode ser entendida como o "elemento essencial de identidade de um lugar" (ABREU, 1998, p. 82), o qual em se tratando do objeto de estudo denominado Cidade implica na extensão do acontecimento solidário, o que remete à obrigação de se viver junto, haja vista que os seres humanos são, por natureza, gregários. Daí que, o lugar é o locus coletivo, do intersubjetivo. Por conseguinte, a análise da memória da cidade prioriza a que for "coletiva", viva, e não a individual, conforme indicado pelo sociólogo francês Maurice Halbwachs (1990). Isso porque a memória da cidade equivale a um estoque de lembranças (eventos, sentimentos) que estão eternizadas na paisagem ou nos registros de um determinado lugar e passam a ser apropriadas pela sociedade, o que permite associações com a linguagem, o discurso, a identidade, a imagem, o cotidiano, etc.

A cidade que precisa de análise, contudo, é a real e concreta porque a ideal é abstrata. Isso implica que o dinamismo e conteúdo da cidade revelam o porquê das benesses, os conflitos e contradições derivados do contexto histórico e de uma população que é caracteristicamente heterogênea, adulta e repleta de memórias.

\section{MEMÓRIA E SENTIDO NA CIDADE DE SÃO LUÍS}

\section{O princípio}

Articular Memória e Sentido em uma cidade que se particulariza por ser capital de um dos estados mais pobres do Nordeste do Brasil (Figura 1) e que completou quatrocentos anos em 2012 não é tarefa simples, sobretudo quando de um lado o discurso oficial tenta impor potencialidades logísticas, culturais, turísticas, ao mesmo tempo que mascara a realidade; por outro lado, essa forma espacial já foi/ é denominada de "Atenas brasileira", "Ilha do Amor", "Jamaica brasileira" e "Região Metropolitana da Grande São Luís", o que só pode ser compreendido em função de diferentes contextos históricos.

Portanto, a preocupação com tal articulação é derivada dessa comemoração, por exemplo, foi relativamente indicada em Corrêa (2008) através do "Projeto UFMA São Luís 400 anos". Isto exige, por sua vez, que se instigue o leitor a apreender o conteúdo das mudanças ocorridas e/ ou em curso, cuja referência é a periodização de Ferreira (2014). 
Convém ressaltar que apesar de controvérsias sobre a fundação francesa de São Luís em 08/09/1612, se utiliza aqui tal data porque é a oficial ${ }^{1}$. Enquanto núcleo de povoação, São Luís foi retomado pelos portugueses em 04/11/1615, passando à categoria de vila em 09/12/1619 com a instalação do Senado da Câmara e à de cidade devido ao ato do Papa Inocêncio XI mediante a Bula "Super Universas Orbis Ecclesia", de 30/08/1677, a qual criou o bispado do Maranhão (MEIRELES, 2012). A partir de então essa cidade passou por momentos de ascensão e chegou a ser considerada a quarta do País em 1822 (SPIX; MARTIUS, 1981), estagnação/declínio na década de 1950 (GEIGER, 1963) e incremento a contar de 1985 (FERREIRA, 2014).

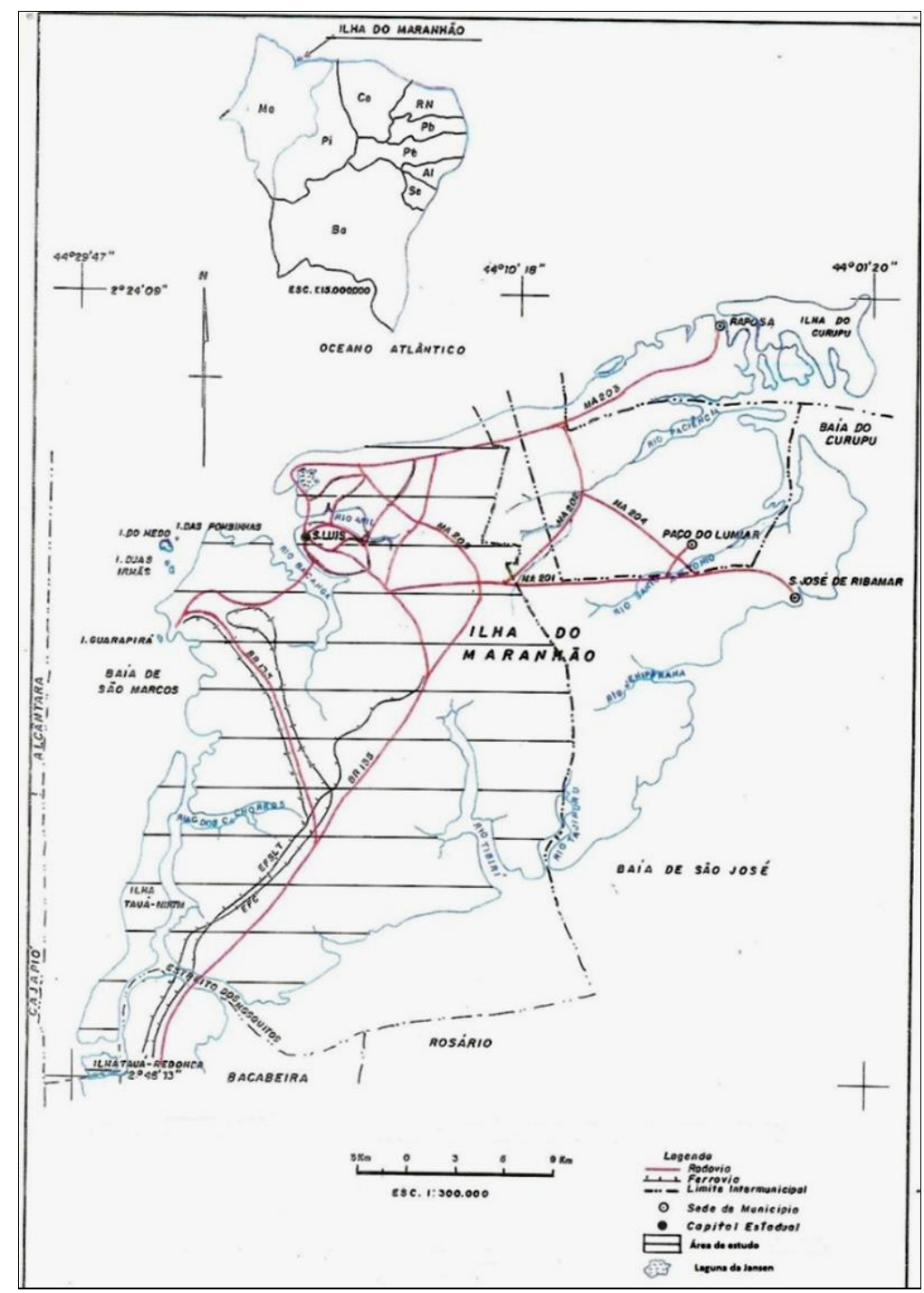

Figura 1 - Mapa da divisão política da aglomeração urbana de São Luís, 2016 Fonte: FERREIRA, 2014.

\footnotetext{
${ }^{1}$ Vale ressaltar que, para Lacroix (2008), a capital maranhense foi fundada pelos portugueses uma vez que o pouco tempo que os franceses permaneceram na ilha do Maranhão (1612-1615) foi insuficiente para estabelecerem uma colônia; ante o revisionismo que está em voga, o historiador Mário Martins Meireles, prudentemente, advogava que o mais correto era sobressair que São Luís é uma cidade portuguesa que nasceu francesa.
} 
Como reflexo de todo esse processo, o centro histórico de São Luís que é composto por 5.607 imóveis distribuídos em 220 hectares foi tombado por legislação federal, estadual e municipal, dos quais 1.369 imóveis foram reconhecidos como Patrimônio Cultural da Humanidade pela UNESCO, em 1997. Os fatos citados anteriormente indicam relativo tempo em que conteúdos afloram, impõem modificações, revelam sentidos e deixam de forma implícita ou explícita memórias diversas. Em termos de ocupação territorial que sintetiza o dinamismo a que foi/ está submetida e que registra incremento, inicialmente, a mesma foi lenta haja vista que demorou 338 anos (1612-1950) para equivaler a apenas $7,17 \mathrm{~km}^{2}$. Mas a concentração de unidades têxteis fabris no final do século XIX denotava, já no início do século XX, conteúdo ímpar em relação a outros núcleos urbanos do País, pois:

[...] as sirenes matutinas e, nas ruas, o movimento de operários e operárias que, apressadamente, se dirigiam para toda a parte em roupas de trabalho, denotavam que um grande número de fábricas, notadamente de tecidos e de fiação, estava em atividade desde as primeiras horas da manhã. Aprofundando mais ainda essa observação e buscando as origens desse intenso labor das indústrias, ver-se-ia que fora o Maranhão, no Norte do Brasil, o pioneiro da tecelagem e de variadíssimas indústrias, infelizmente desprezadas em grande parte já naquela época. (MACEDO, 2001, p. 68).

O mencionado processo de ocupação de forma lenta, por outro lado, concorreu para que o Estado investisse na estruturação da capital maranhense por intermédio de equipamentos como abastecimento d'água via chafariz público (1856), substituição da iluminação a azeite pela de gás de hidrogênio (1863), bonde (1870), telefone (1890), luz e tração elétrica (1918), os quais revelavam a "modernidade" exigida pela elite que ditava comportamentos na vida cotidiana porque "São Luís acompanhava de perto a Corte" (PAXECO, 1922, p. 106), mas emergia a segregação socioespacial através de palafita (Macaúba) e área de ocupação (Fátima), que derivou de um passado de escravismo, o qual desde o período colonial até o fim do tráfico negreiro sustentou a economia do Maranhão.

Conforme evidenciado no Quadro 1, a lentidão do crescimento horizontal de São Luís, entre 1612-1950, foi redimensionada porque em quarenta e cinco anos (1951-1996) a ocupação expandiu-se e atingiu 282,07 km² que arrefeceu entre 2000 e 2010, pois a área ocupada atingiu $36,56 \mathrm{~km}^{2}$. Paralelamente, esses períodos revelavam a modernização dessa cidade e notórias contradições passíveis de memória. 
Quadro 1 - Cidade de São Luís: crescimento horizontal, 1612-2010

\begin{tabular}{|c|c|}
\hline Período & Área ocupada $\left(\mathbf{k m}^{2}\right)$ \\
\hline $1612-1950$ & 7,17 \\
\hline $1951-1996$ & 282,07 \\
\hline $2000-2010$ & 36,56 \\
\hline
\end{tabular}

Fonte: FERREIRA, 2014.

\section{A memória enquanto possibilidade de análise}

Desse contexto tem-se que as memórias inerentes à São Luís de 1612 a 1950 remontam às descrições das passagens de colonizadores (D'ABBEVILLE, 1614) e viajantes (AZEVEDO, 1950/51; SPIX; MARTIUS, 1981; CALDEIRA, 1991), que avançam pelas compras na Rua Grande (principal área comercial) e abarcam os filmes do Cinema Palace, Cine Teatro Éden, Rivoli e Cine Anil, assim como as praças que eram locais de reuniões, entre as quais a do Largo do Carmo era considerada "o coração da cidade" (VIEIRA FILHO, 1971, p. 107) em que a noite instalava-se o "Senado da Praça" e o DIVA (Departamento de Informação da Vida Alheia). Também destacavam-se as "barbearias", a exemplo do Salão Central e da extinta Pompeu, as quais retratam o momento final desse primeiro período no qual "a freguesia andava de calça de linho e que ir à barbearia era chique [...], pois vinha-se com a melhor roupa, de terno e gravata" (MELLO, 2009, p. 12). Os contatos interpessoais do segundo período (1951-1996), por seu turno, eram paroquiais e destacavam-se pelo "olá", "bom dia", "boa tarde", "como vai"? O tratamento nos povoados era primordialmente o "compadre". O preço do solo, ainda baixo na metade desse período, era quase desconsiderado e desse modo, praticamente não existia a figura do corretor de imóveis e as incorporadoras, sendo que, assim, predominava a "cessão" do imóvel para o amigo, o parente ou até mesmo para o "desconhecido" e "com aparência de legal", o qual deveria se incumbir da não deterioração do imóvel (FERREIRA, 2009).

Tais memórias têm vinculação direta com o cotidiano e mascaram outros elementos passíveis de análise. Por exemplo:

Primeiro, a população expropriada/ remanejada para instalação de indústrias na década de 1980 tinha relação harmônica com o lugar que escolheu para viver no município de São Luís. Por conseguinte, ela teve que adaptar-se a um novo lugar, nova forma de habitação, novas relações sociais e até mesmo o exercício de outra profissão, ou seja, novas adaptações à cidade e submissão ao urbano, bem como houve a desarticulação da família, 
da comunidade e a resistência para manter a posse na área de mangue ou na terra firme recém-ocupada.

Segundo, com os empreendimentos dessa década, a concepção de modernidade foi implantada para atender a demanda de uma faixa privilegiada da população que enquanto consumidora e assentada em "sistema de valores" (CARLOS, 1995, p. 1) tipicamente urbanos, exigia mais "sofisticadas" lojas de departamento, shopping centers, ampliação e distribuição espacial de estabelecimentos bancários, restaurantes, boites, serviços especializados e o "novo conceito de moradia" (apartamento) imposto pelo mercado imobiliário. Por conseguinte, o ritmo da cidade passou de "lento" para "rápido" ou "mecânico" enquanto os cumprimentos provincianos foram substituídos pela indiferença, o estranhamento e até o medo do outro.

Terceiro, enquanto isso ocorria, uma faixa da população se reconhecia e/ ou criava identidade na referida cidade por intermédio de áreas de lazer que já não eram mais a Zona do Baixo Meretrício (REIS, 2002), pois haviam surgido os clubes sociais (Moto, Casino, Lítero, Jaguarema) e as praças, porém os clubes de reggae, as associações de "filhos"/ "irmãos" / "amigos" de vários municípios do interior do Maranhão, como a de Barreirinhas e Pinheirense (FERREIRA, 2009).

Assim, fica evidenciado que novos elementos de análise continuam emergindo nessa cidade em decorrência da implantação de empreendimentos econômicos, a exemplo de "novos lançamentos do ramo imobiliário" (MORAES, 2013), bem como aos relativos ao segmento comercial, além da apropriação da terra rural devido às unidades do Programa Minha Casa Minha Vida (MCMV) e aos condomínios particulares.

Por tais razões, a contemporânea São Luís é bem diferente daquela ilustrada por Gaudêncio Cunha (apud SILVA FILHO, 2012) em "a cidade no tempo", que cobriu o período de 1908 a 2008 (RAMOS, 2008) e cujas memórias são fotográficas. Também é diferente da cidade descrita pelo poeta Ferreira Gullar em "Poema Sujo" ou da que foi enaltecida pelo cantor e compositor Papete, na magistral "Sobrados" em que releva: "Onde está minha cidade? Onde está meu coração?”. As disparidades desses quatrocentos anos de História foram sintetizadas em "corpo e alma" de Lacroix (2012) em que houve destaque para uma "cidade traçada" (século XVII), o "início da expansão" (século XVIII), a "era do casario" (século XIX), além do "crescimento e degradação" (século XX). Há, ainda, uma memória que se pretende esquecer porque evidencia insalubridade, más condições de trabalho, doença e morte, cujas referências são as ocorrências de varíola $(1621,1695,1724$, 1776, 1890 e 1908), febre amarela (1851), peste bubônica (1903) e tuberculose (1917), de 
maneira que esforços de discussão estão contidos em Rodrigues (2010) e Almeida (2012) porque a saúde (entenda-se qualidade de vida) permanece na ordem do dia.

\section{A cidade não para}

O fato é que a cidade não para. Por exemplo, conforme o censo demográfico de 1940, a cidade de São Luís possuía 60.966 habitantes de um total de 85.583 moradores desse município, que, em 2010, avançaram para 1.014 .837 residentes dos quais $94,5 \%$ moravam na zona urbana enquanto 5,5\% residiam na zona rural (Gráfico 1), distribuídos em 363 localidades com destaque para 218 bairros, cinquenta sítios e 95 povoados; a capital maranhense concentra a frota de veículos, as agências bancárias, o Produto Interno Bruto, a logística entorno do complexo portuário, a prestação de bens e serviços, além dos melhores equipamentos em termos de educação e saúde do estado referido (FERREIRA, 2014).

Nesse contexto, nos questionamos: qual conteúdo emergiu? Que memórias ainda persistem?

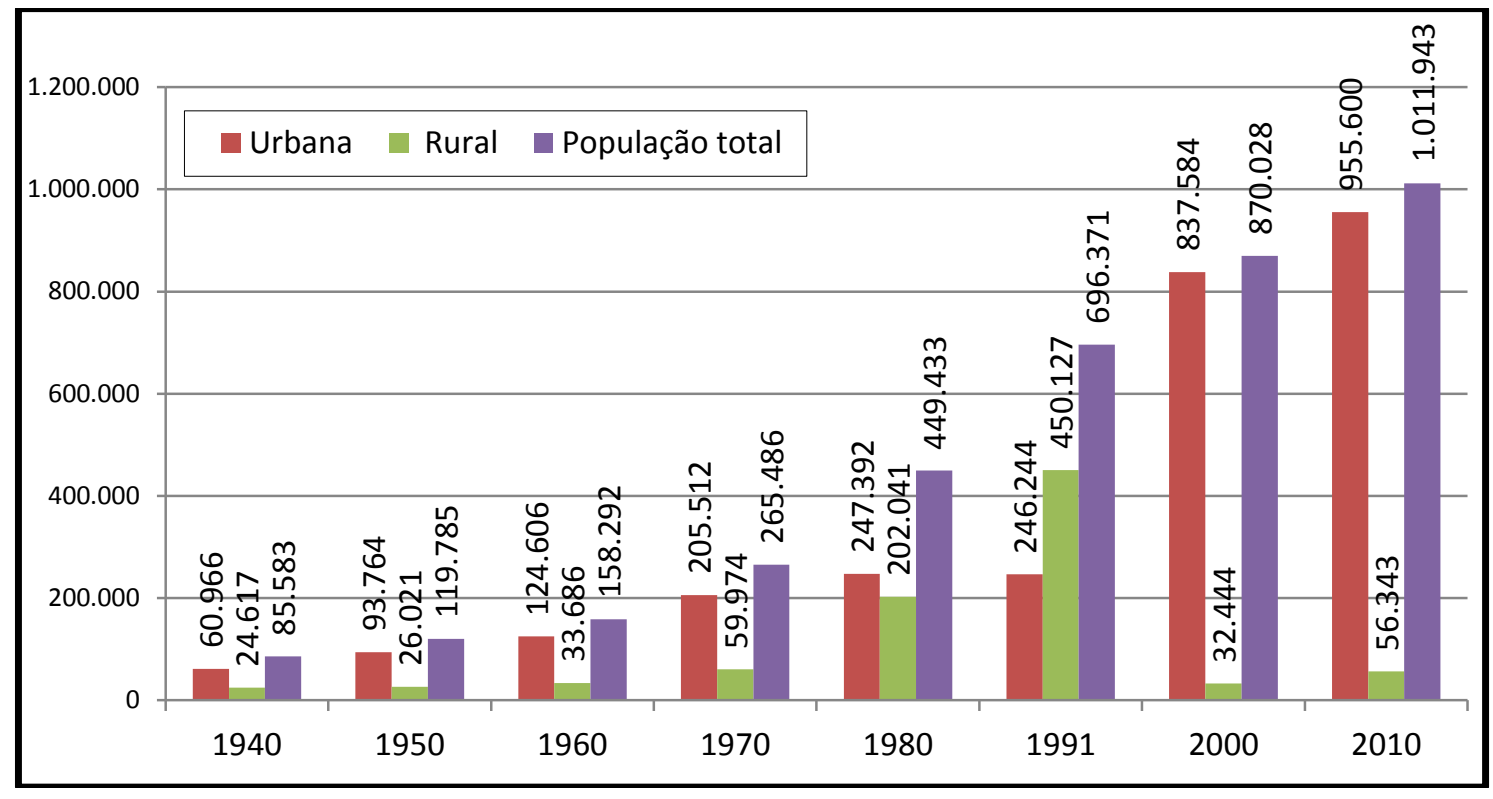

Gráfico 1 - São Luís: evolução da população, 1940-2010

Fonte: FERREIRA, 2014.

Apesar dos sucessivos códigos de posturas e principalmente dos planos diretores de São Luís, que foram instituídos nos anos de 1974, 1992 e 2006, os quais simbolizam certa preocupação e alguma memória de gestores públicos almejando ao disciplinamento do uso e ocupação do solo, o que se constata é que houve agravamento de problemas que decorrem de fatores como: ampliação dos riscos de acidentes devido à ocupação de áreas 
impróprias (Salina do Sacavém, Coroadinho, Sá Viana); a contaminação de águas superficiais, subterrâneas e do solo que impede um simples banho no rio e/ ou praia; assim, persistem problemas relacionados à saúde ocasionados pelo "negligenciamento e a dengue" (MASULO, 2013); o congestionamento nas vias de acesso concorre para atrasos e/ ou adiamento de compromissos; o comprometimento do patrimônio histórico-cultural e o da qualidade de vida da população são notórios, o que se torna empecilho para atividades indutoras como o turismo e, sobretudo, para o usufruto da cidade por parte do cidadão que mora em São Luís.

Tais problemas trazem à tona sentimentos e memórias não muito distantes em relação às pessoas de idade mais avançada (avós, mães, pais e tios), principalmente quando procuram-se respostas para: você tinha medo de morar na cidade? Era saudável banhar em rios de águas límpidas e praias "selvagens"? Apesar de lento, o bonde aproximava as pessoas que não se arvoravam do automóvel particular? Vc usava a praça enquanto lugar para namorar, conversar e discutir futebol e/ ou política? Os arraiais das festas juninas, que particularizam a riqueza das manifestações culturais da capital maranhense, gradativamente, saíram dos bairros e em nome da segurança e do espetáculo materializam-se nos shopping centers (Figura 2) e redimensionam o cotidiano (FERREIRA, L. M., 2012).

Essas ponderações remetem a memórias que dão sentido à cidade de São Luís, o que requer melhor apreensão e têm diferentes formas de serem analisadas. Para tanto, é importante recorrer à história oral pela rememoração dos velhos, à iconografia, à linguagem, ao discurso, à poesia, ao cinema, ao croqui, ao romance 2 .

2 Cf.: MEMÓRIA DE VELHOS. Depoimentos. Uma contribuição à memória oral da cultura popular maranhense, Vol. I, II, III, e IV. São Luís: SEC/CCP Domingos Vieira Filho, Lithograf, 1997. MOREIRA, Euclides. Primórdios do cinema em São Luís. São Luís: UFMA, s/d. 


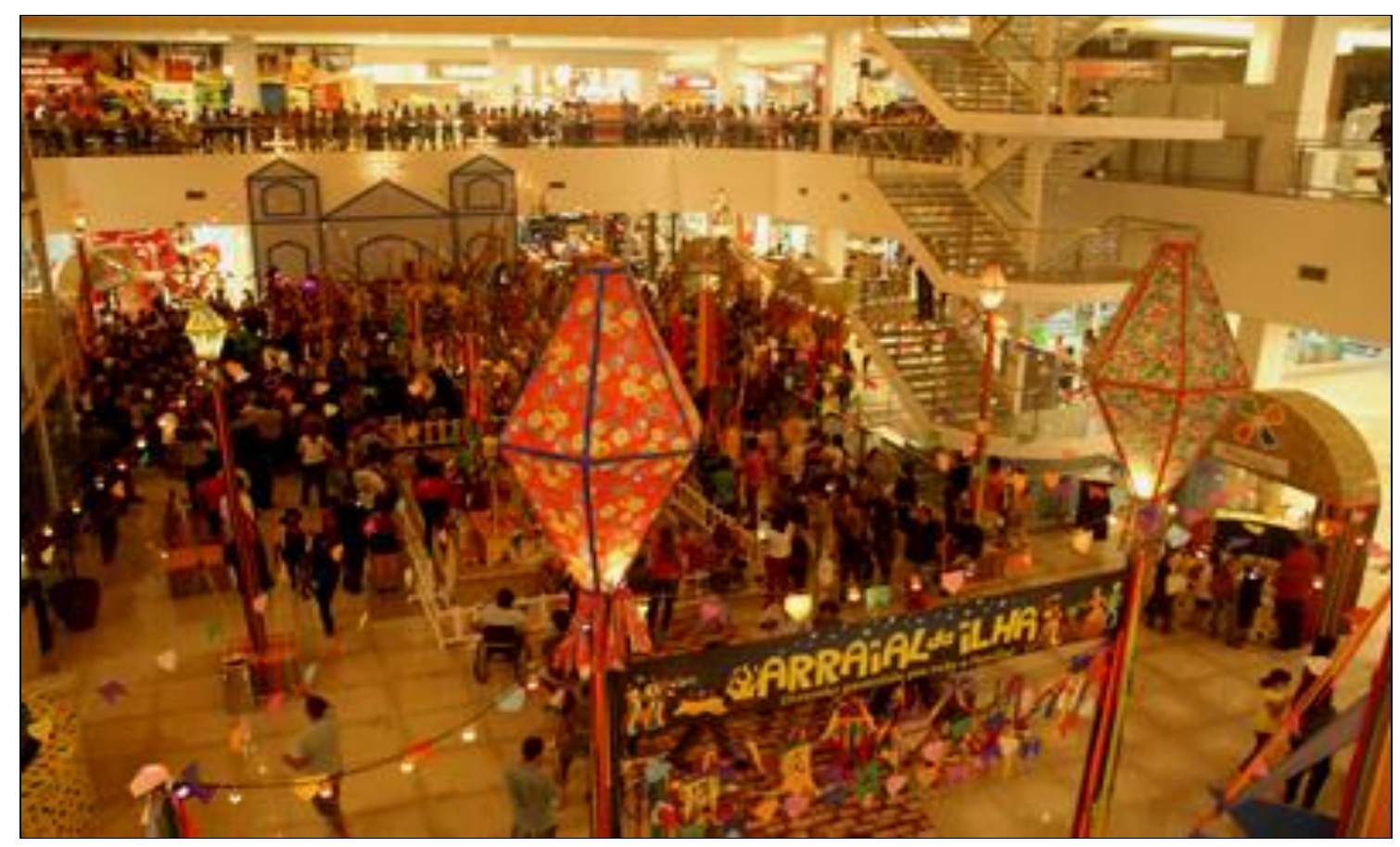

Figura 2 - Arraial da Ilha, Praça de Eventos do Shopping da Ilha Fonte: FERREIRA, Lucimary M., 2012.

Nesse sentido, contextualizando com o que foi posto anteriormente, a Geografia Histórica Urbana pode se apresentar como um excelente fio condutor dessa problematização. Isso porque, enquanto o conteúdo da cidade de São Luís se transformava e uma gama de problemas era conhecida desde o final da década de noventa do século XX através do programa estadual de zoneamento costeiro, as ações foram tímidas e a justificativa era a falta de planejamento.

Com efeito, os problemas vão ampliaram-se gradativamente e somente são colocados em pauta na "época" das comemorações de aniversário da cidade referida, cujo ápice ocorreu nas festividades do quarto centenário. Nestas, o Conselho Estadual das Cidades do Maranhão levou a cabo o "Seminário São Luís +400 anos: discutindo a região central e a metrópole sob a luz do estatuto da cidade" em que a memória dos presentes em tal evento, que aconteceu nos dias 22 e 23/08/2012, sobressaiu os já conhecidos problemas de habitação, saneamento básico, mobilidade/acessibilidade, além de planejamento e gestão do solo.

Assim, passados dez meses da realização desse evento, o movimento da capital maranhense intitulado "Vem Prá Rua São Luís", que ecoou o MPL paulistano e a "passeata dos cem mil" da capital carioca, reuniu 15.000 pessoas no dia 19/06/2013, impondo a necessidade da rediscussão democrática dos problemas reais concentrados nas cidades 
brasileiras e que se rebatem e particularizam no cotidiano de todo cidadão que deve ter “direito à cidade", predominantemente, com qualidade de vida.

Em termos de futuro, a cidade de São Luís tem sido incluída em uma gama de planos e projetos os quais priorizam melhoria da logística, retomada de investimentos no setor habitacional, intervenções almejando à otimização da mobilidade (Avenida Quarto Centenário, Transmetropolitana, Via Expressa, Veículo Leve sobre Trilhos), ampliação e atração de empreendimentos econômicos, o que culminará em crescimento demográfico e dinamismo mais acentuado. O poder de gestão, por sua vez, precisa utilizar instrumentos e políticas públicas que visem à resolução (ou pelo menos amenização) dos permanentes problemas elencados, conhecidos e discutidos na sexta Conferência da Cidade de São Luís, que aconteceu nos dias 4 e 5 de julho de 2016. Isso porque tais problemáticas já travam a funcionalidade dessa capital e, concomitantemente, qualquer intervenção precisa relevar a qualidade de vida dos cidadãos a fim de prepará-la, melhor, para as comemorações do quinto centenário.

\section{CONCLUSÕES}

O crescimento urbano de São Luís pode ser analisado a partir do Sentido e da Memória dessa cidade que completou quatro séculos em 2012. Nesse caso, convém não se enveredar por abordagens setorizadas já que podem servir de exemplos passíveis de análise: a utilização das praças por jovens, adultos e idosos que brincavam e discutiam/ faziam política, assim como falavam da "vida alheia"; as "barbearias" também eram ponto de encontro e conversa; o vestuário era mais elegante e próximo do que se usava na Corte; o bonde era o meio de transporte; a Rua Grande era a principal via de comércio. O sentido dessa cidade e suas memórias revelam conteúdos/ elementos passíveis de análise e que denotam transformações em que a Geografia Histórica Urbana aponta excelente caminho.

A partir de 1950, assim, a concepção de "modernidade" foi incrementada por intermédio de sucessivas substituições que incluem: o desuso das praças e das barbearias; shopping centers foram instalados e impuseram novas centralidades quando comparada à importância da Rua Grande e até aos "mais seguros" arraiais juninos; o ônibus e o automóvel particular facilitaram deslocamentos, porém o aumento da frota culminou em congestionamentos; clubes sociais perderam relevância e espaço para boites, Avenida Litorânea, os clubes de reggae; o almoço familiar é cada vez mais raro e a falta de tempo resultou no "almoçar/ jantar" à frente da televisão; em nome da segurança, o morar em 
casa tem sido sobreposto pelo apartamento e pelos condomínios, mas as palafitas e áreas de ocupação continuam crescendo e colocando em xeque a política habitacional, apesar do MCMV; a cidade se expande tanto horizontal quanto verticalmente. $O$ mencionado crescimento urbano revelou, ainda, uma face social em que os contatos interpessoais de caráter provinciano foram relegados pelo individualismo e o estranhamento. Também culminou na degradação ambiental e vários tipos de poluição, que emergiram na contemporaneidade. A memória, portanto, aflorou, teve seu conteúdo modificado e se ramifica em várias possibilidades de análise, entre as quais o ano de 2013 revelou a ação política por intermédio da retomada de praças, ruas e avenidas a fim de recolocar no debate os ineficientes serviços públicos e a não efetivação da Reforma Urbana Já.

A apreensão do Sentido e da Memória da Cidade, em particular os da capital maranhense, por isso requer esforços mais audaciosos e comprometidos com a transformação da realidade social porque a população continua, cheia de esperanças, direcionando-se para um núcleo urbano em que evidencia-se a fraca memória e o futuro parece incerto. Os indícios revelam, felizmente, o resgate de memórias combativas e questionadoras através do movimento "Vem Prá Rua São Luís", que passou a ser a referência promissora.

\section{REFERÊNCIAS}

ABREU, Maurício de A. Sobre a memória das cidades. Revista da Faculdade de Letras Geografia I, Porto, v. 14, p. 77-97, 1998.

ALMEIDA, Maria da C. P. de. O estado sanitário da cidade de São Luís no início do século XX. In: ABRANTES, Elizabeth S.; SANTOS, Sandra R. R. dos (Org.). São Luís do Maranhão: novos olhares sobre a cidade. São Luís: Ed. UEMA, 2012, p. 131-154.

AZEVEDO, Aroldo de. São Luiz do Maranhão (primeiros estudos). In: ASSOCIAÇÃO DOS GEÓGRAFOS BRASILEIROS, v. V, t. 1, 1950/51., São Paulo. Anais... Salvador: AGB, 1950/51.

BAUMAN, Zygmunt. Confiança e medo na cidade. Rio de Janeiro: Zahar Ed., 2009.

BOSI, Ecléa. Memórias da cidade: lembranças paulistanas. Estudos Avançados, São Paulo, v. 17, n. 47, p. 197-211, 2003.

CALDEIRA, José de R. O Maranhão na literatura dos viajantes do século XIX. São Luís: AML/SIOGE, 1991.

CARLOS, Ana Fani A. et al. (Org.). A cidade como negócio. São Paulo: Contexto, 2015. 
CARLOS, Ana F. A. A construção de uma "nova urbanidade". São Paulo: Contexto, 1995.

CORRÊA, Alexandre F. Projeto UFMA São Luís 400 anos. In: ENCONTRO HUMANÍSTICO, 7, 2008, São Luís. Anais... São Luís: Edufma, 2008, p. 89-97.

CLARK, David. Introdução à geografia urbana. 2. ed. Rio de Janeiro: Bertrand Brasil, 1991.

D'ABBEVILLE, Claude. História da missão dos padres capuchinhos na Ilha do Maranhão e terras circunvizinhas. Belo Horizonte: Itatiaia/São Paulo: EDUSP, 1975 [1614]. v. 19.

FERREIRA, Antonio J. de A. A produção do espaço urbano em São Luís do Maranhão: passado e presente; há futuro. São Luís: EDUFMA, 2014.

São Luís do Maranhão: em que cidade vivemos? Que cidade queremos no quarto centenário? Ciências Humanas em Revista, São Luís, v. 7, n. 2, 2009.

FERREIRA, Lucimary M. O shopping center e suas repercussões no cotidiano da população da cidade de São Luís-MA. 2012. Monografia (Graduação em Geografia) Departamento de Geociências, Universidade Federal do Maranhão, São Luís, 2012.

GEIGER, Pedro P. A evolução da rede urbana brasileira. Rio de Janeiro: INEP, 1963.

HALBWACHS, Maurice. A memória coletiva. São Paulo: Vértice, 1990.

HARVEY, David. A justiça social e a cidade. São Paulo: Hucitec, 1980.

A produção capitalista do espaço. São Paulo: Annablume, 2005.

O enigma do capital. Lisboa: Editorial Bizâncio, 2011.

Cidades rebeldes. São Paulo: Martins Fontes, 2014.

HELLER, Agnes. O cotidiano e a história. 2. ed. Rio de Janeiro: Paz e Terra, 1985.

LACROIX, Maria de L. L. A fundação francesa de São Luís e seus mitos. 3. ed. São Luís: Editora UEMA, 2008.

São Luís do Maranhão: corpo e alma. São Luís: Eduema, 2012.

LEFEBVRE, Henri. La vida cotidiana en el mundo moderno. 3. ed. Madrid: Alianza Editorial, 1984.

MACEDO, Eurico T. de. O Maranhão e suas riquezas. São Paulo: Siciliano, 2001.

MASULO, Yata A. G. Avaliação da dinâmica espacial da dengue em relação às questões socioambientais no distrito sanitário da Cohab no município de São Luís - MA. 2013. Relatório de Qualificação (Mestrado em Desenvolvimento Socioespacial e Regional) - Centro de Ciências Sociais Aplicadas, Programa de Pós-Graduação em 
Desenvolvimento Socioespacial e Regional, Universidade Estadual do Maranhão, São Luís, 2013.

MELLO, Carolina. SÓ para cavalheiros. O Imparcial, São Luís, 8 nov. 2009, p. 12 e 13.

MEIRELES, Mário. História de São Luís. São Luís: Faculdade Santa Fé, 2012.

MORAES, Josenilde C. D. de. A lógica da produção do espaço urbano do condomínio Farol da Ilha na reprodução do capital em São Luís (MA). 2013. Relatório de Qualificação (Mestrado em Desenvolvimento Socioespacial e Regional) - Centro de Ciências Sociais Aplicadas, Programa de Pós-Graduação em Desenvolvimento Socioespacial e Regional, Universidade Estadual do Maranhão, São Luís, 2013.

OLIVEIRA, Floriano G. de. et al. (Org.). Geografia urbana: ciência e ação política. Rio de Janeiro: Consequência, 2014.

PAXECO, Fran. Geografia do Maranhão. São Luís: Typogravura Teixeira, 1922.

RAMOS, Albani. São Luís, 1908 * 2008 - a cidade no tempo. São Luís: Instituto da cidade, 2008.

REIS, José R. S. dos. ZBM: o reino encantado da boemia. São Luís: Litograf, 2002.

RODRIGUES, Zulimar M. R. Sistema de indicadores e desigualdade socioambiental intraurbana de São Luís-MA. 2010. Tese (Doutorado em Geografia Humana) Faculdade de Filosofia, Letras e Ciências Humanas, Programa de Pós-Graduação em Graduação em Geografia Humana, Universidade de São Paulo, São Paulo, 2010.

SANTOS, Antonio C. de A. Memórias e cidade: depoimentos e transformação urbana de Curitiba (1930-1990). 1995. Dissertação (Mestrado em História) - Departamento de História, Universidade Federal do Paraná, Curitiba, 1995.

SANTOS, Milton. A urbanização brasileira. São Paulo: Hucitec, 1994.

O espaço do cidadão. 7. ed. São Paulo: Edusp, 2007.

SARAMAGO, José. Ensaio sobre a cegueira. São Paulo: Companhia das Letras, 1995.

SILVA, José Afonso de. Direito urbanístico brasileiro. 2. ed. São Paulo: Malheiros Editores Ltda., 1997.

SILVA FILHO, José O. de. A história capturada: São Luís pelas lentes de Gaudêncio Cunha (1895-1908). São Luís: Eduema, 2012.

SPIX, J. B. von; MARTIUS, C. F. P. von. Viagem ao Brasil: 1817/1820. 2. ed. Belo Horizonte: Editora Itatiaia, 1981.

SPÓSITO, Maria E. B. (Org.). Cidades médias: espaços em transição. São Paulo: Expressão Popular, 2007. 
Memória e sentido a partir da cidade de São Luís do Maranhão Antonio José de Araújo Ferreira

VIEIRA FILHO, Domingos. Breve história das ruas e praças de São Luís. São Luís, 1971.

Recebido para avaliação em 31/07/2016

Aceito para publicação em 23/04/2017 